\title{
Bcl-2 Overexpression Does Not Enhance In Vivo Axonal Regeneration of Retinal Ganglion Cells after Peripheral Nerve Transplantation in Adult Mice
}

\author{
Tetsu Inoue, ${ }^{1}$ Mizuho Hosokawa, ${ }^{1,2}$ Katsuko Morigiwa, ${ }^{1}$ Yuichi Ohashi, ${ }^{2}$ and Yutaka Fukuda $^{1}$ \\ ${ }^{1}$ Department of Physiology and Biosignaling, Graduate School of Medicine, Osaka University, Osaka 565-0871, Japan, \\ and ${ }^{2}$ Department of Ophthalmology, School of Medicine, Ehime University, Ehime 791-0295, Japan
}

Optic nerve $(\mathrm{ON})$ injury in adult mammals causes retinal ganglion cell (RGC) death and subsequent visual loss. Recovery of vision requires both rescuing axotomized RGCs and inducing their axonal regeneration. Axotomized RGCs are significantly rescued by overexpression of $b c /-2$, an anti-apoptotic gene. However, whether $b c /-2$ affects axonal regeneration is controversial. In neonatal $b c /-2$ transgenic mice (bcl-2 mice), optic tract regeneration after tectal lesion was promoted (Chen et al., 1997), whereas ON regeneration after ON crush was not (Lodovichi et al., 2001). These conflicting results may be attributable to different environments between tectum and ON. We tested here whether $b c /-2$ overexpression enhances in vivo RGC axonal regeneration in adult mice through a permissive environment in the peripheral nerve (PN) graft. Four weeks after PN transplantation to the proximal ON stump, we assessed the number of surviving and regenerating RGCs by retrograde la- beling. Although the survival rate in $b c /-2$ mice was significantly enhanced compared with that in wild-type (wt) mice, the regeneration rate was not enhanced. In both bcl-2 and wt mice, RT97 immunostaining of the PN-grafted retinas revealed some RGC axons regrowing intraretinally but repulsed at the optic disk. To circumvent this repulsive barrier, we directly transplanted the PN graft to the partially injured retina and compared regeneration rates between these mice. Here again the regeneration rate in $b c /-2$ mice did not exceed that in wt mice. These findings indicate that $b c /-2$ overexpression enhances survival but not axonal regeneration of adult RGCs even within a permissive environment.

Key words: axonal regeneration; survival; retinal ganglion cells; peripheral nerve transplantation; optic nerve; bcl-2 transgenic mice
In adult mammals, optic nerve $(\mathrm{ON})$ transection results in retrograde degeneration of retinal ganglion cells (RGCs) and ultimate loss of visual function. However, when a segment of peripheral nerve $(\mathrm{PN})$ is transplanted to the transected site, RGC axons can regenerate for a long distance (Vidal-Sanz et al., 1987). Furthermore, when these regenerating axons are guided to midbrain visual centers through the PN graft, they make functional synapses with target cells (Vidal-Sanz et al., 1987). The transplanted animals have been shown to recover some visual functions such as pupilloconstriction and light-dark discrimination (Thanos, 1992; Sasaki et al., 1993). However, PN transplantation alone promotes regeneration of only $5 \%$ of RGC axons, probably enough for restoration of rudimentary visual functions but not for higher visual functions such as discrimination of light intensities and visual patterns. For the recovery of these functions, a substantial number of RGCs need to survive and to regenerate their axons.

Received Dec. 6, 2001; revised March 15, 2002; accepted March 19, 2002.

This study was supported by Strategic Promotion System for Brain Science by Special Coordination Funds for Promoting Science and Technology, Japan, Grantin-Aid 10770931 for Scientific Research on Priority Areas from the Ministry of Education, Science, Sports and Culture of Japan, and an Osaka Eyebank Research Grant-in-aid. We thank Dr. Y. Tsujimoto and GlaxoWelcome Ltd. Tsukuba Research Laboratories for kindly providing the $b c l-2$ mice. We thank Dr. M. Z. Quan, Senjyu Pharmaceutical Co. Ltd., for instruction in RT97 immunohistology. We thank Dr. A. T. Ishida and Dr. H. Sawai for constructive comment on this manuscript.

Correspondence should be addressed to Dr. Tetsu Inoue, Department of Physiology and Biosignaling, Osaka University Graduate School of Medicine A5, 2-2 Yamadaoka, Suita, Osaka 565-0871, Japan. E-mail: tinoue@phys2.med.osakau.ac.jp.

Copyright (C) 2002 Society for Neuroscience $0270-6474 / 02 / 224468-10 \$ 15.00 / 0$
Many attempts have been made to enhance the survival and axonal regeneration of adult RGCs. Intraocular injections of microglia inhibitors or CNTF enhance the survival and axonal regeneration of RGCs through PN grafts (Mey and Thanos, 1993; Thanos et al., 1993; Cui et al., 1999) but only to $~ 20 \%$ of the total RGCs. Most axotomized RGCs undergo apoptotic cell death (Bähr, 2000), and consistent with this, overexpression of the anti-apoptotic $b c l-2$ gene enhanced RGC survival to $\sim 65 \% 3.5$ months after axotomy in adult mice (Cenni et al., 1996). Thus protection from apoptotic cell death has been considered a prerequisite to achieve robust RGC axonal regeneration. Moreover, Chen et al. (1997) have indicated that $b c l-2$ overexpression directly enhances the process outgrowth of embryonic day (E) 14 to postnatal day (P) 5 mouse retinal neurons in retino-tectal cocultures as well as in in vivo tectal lesions in P5 mice. However, when the ON was crushed in an in vivo study on P5 bcl-2 mice, RGC axons failed to regenerate (Lodovichi et al., 2001). In adult $b c l-2$ mice, neutralization of the myelin-associated inhibitory factor (IN-1 antibody) did not allow axonal regeneration of RGCs through the crushed ON (Chierzi et al., 1999). Consistent with these results, a recent dissociated cell culture study of E19 and P8 rats suggested that $b c l-2$ overexpression did not promote axonal elongation even in the presence of BDNF, CNTF, and forskolin (Goldberg and Barres, 2000). Thus it is still uncertain whether $b c l-2$ overexpression by itself can enhance the axonal regeneration of RGCs.

The effect of $b c l-2$ overexpression on in vivo axonal regeneration of axotomized adult RGCs has not yet been studied. Here we attempted to assess the number of regenerating RGCs in adult 


\begin{tabular}{lll}
\hline Table 1. Contents of experiments and number of mice & \\
& $w t$ & $b c l-2$ \\
\hline Retrobulbar PN transplantation group & 17 & 13 \\
$\quad$ Observation of the grafted site & 3 & - \\
Assessing axonal regeneration & & \\
$\quad$ Retrograde labeling of surviving RGCs & 5 & 4 \\
$\quad$ Retrograde labeling of regenerating RGCs & $9(3)$ & $9(3)$ \\
Intraretinal PN transplantation group & 6 & 6 \\
$\quad$ Assessing axonal regeneration (retrograde & & \\
labeling of surviving RGCs) & $6(5)$ & $6(4)$ \\
Non-transplantation group & 6 & 5 \\
$\quad$ Retrograde labeling of normal RGCs & 3 & 3 \\
RT97 immunostaining & 3 & 2
\end{tabular}

Numbers in parentheses indicate number of mice processed for RT97 immunostaining after cell counting of retrogradely labeled RGCs.

$b c l-2$ mice compared with that in wt mice. After PN transplantation to the sectioned $\mathrm{ON}$ and also to the partially lesioned retina, we assessed the percentage of regenerating RGCs by retrograde labeling with fluorescent dyes. We report here that there is no evidence that $b c l-2$ overexpression enhances in vivo axonal regeneration of adult RGCs.

A part of this study has been published previously in abstract form (Hosokawa et al., 1999).

\section{MATERIALS AND METHODS}

Animals and experimental design

We used littermates of wt $(n=29)$ and $b c l-2$ mice $(n=24)$ of $4-10$ months of age, which were provided by GlaxoWelcome Ltd. Tsukuba Research Laboratories. In $b c l-2$ mice that were originally produced by Martinou et al. (1994), the human bcl-2 gene is overexpressed under the control of neuron-specific enolase. All procedures for the use of animals were in accordance with the U.S. Public Health Service Policy on Humane Care and Use of Laboratory Animals.

The numbers of animals used in the present experiments are listed in Table 1. The experimental animals were divided into three groups. In a first group (17 wt and $13 \mathrm{bcl}-2 \mathrm{mice}$ ), the PN graft was transplanted to the proximal ON stump [retrobulbar (RB) transplantation]. These animals were used in the following experiments: (1) observation of the ON-PN interface in longitudinal sections; (2) evaluation of survival and regeneration rates based on retrograde labeling of RGCs; and (3) observation of intraretinal RGC axons by RT97 immunostaining in retinal whole mounts. In a second group (six wt and six $b c l-2$ mice), the PN graft was inserted into the retina [intraretinal (IR) transplantation]. These animals were used for evaluation of regeneration rate and for experiment 3 described above. A third group of mice (six wt and five $b c l$-2 mice) received no PN graft and was used to study retrograde labeling of normal RGCs (three wt and three bcl-2 mice) and to provide controls for RT97 immunostaining (three wt and two bcl-2 mice).

\section{Surgical procedures of $R B$ and IR transplantation}

For all surgical procedures, animals were intraperitoneally anesthetized with $15 \times$ sodium pentobarbital solution $(60 \mathrm{mg} / \mathrm{kg}$ body weight; Nembutal, Dainippon Pharmaceutical, Osaka, Japan). During survival intervals between surgical procedures, the animals were housed in cages under $12 \mathrm{hr}$ light/dark cycles, with ad libitum access to food.

RB transplantation was performed as described previously (Vidal-Sanz et al., 1987; Inoue et al., 2000). Briefly, the proximal end of an autologous peroneal nerve graft $(15 \mathrm{~mm}$ in length) was attached to the proximal ON stump at $<1 \mathrm{~mm}$ from the eyeball by three to four stitches to the $\mathrm{ON}$ sheath or the sclera with 11-0 nylon (11-0 Ethilon; Ethicon, Somerville, NJ). IR transplantation was also performed as described previously (So and Aguayo, 1985; Inoue et al., 2000). The eye wall was completely perforated from the scleral side with a 26 gauge needle at the dorsal side of the dorsonasal vorticose vein. The proximal end of the peroneal nerve graft (15 mm in length) was inserted through the scleral perforation toward the retina. At the insertion site, the outer surface of the PN graft was anchored to the sclera by two sutures with 11-0 nylon. The distal part of the graft was laid in the muscle over the skull.

\section{$R B$ transplantation: observation of $O N-P N$ interface}

We used three wt mice to examine whether the PN graft was completely attached to the ON stump and whether the RGC axons regenerated into the graft. To label the regenerating RGC axons within the PN graft, we modified the original anterograde labeling method developed by Thanos et al. (1987). Four weeks after RB transplantation, $3 \mu \mathrm{l}$ of $1 \%$ tetramethylrhodamine isothiocyanate solution (Molecular Probes, Eugene, OR) was intermittently injected into the eyeball for 20 min with a Hamilton syringe (Hamilton Company, Reno, NV). The excess solution that leaked outside the eyeball was immediately wiped away. One day later, the animal was perfused intracardially with $4 \%$ paraformaldehyde, and the eye-ball and the PN graft were removed. The distal half of the PN graft was cut apart from the proximal half of the graft that attached to the eyeball. After $1 \mathrm{hr}$ fixation and cryoprotection with $30 \%$ sucrose (overnight), the specimen was cryosectioned longitudinally $(10 \mu \mathrm{m}$ in thickness). The sections of the distal PN graft were coverslipped with an anti-fading reagent (Vectashield, Burlingame, CA).

\section{Histology}

Each section of the proximal half of the PN graft was immunostained for GFAP-positive astrocytes in the ON stump or for laminin-positive Schwann cells and their basal laminas in the PN graft. The following primary antibodies (Abs) were used: rabbit anti-GFAP Ab (Dako Japan, Kyoto, Japan) and rabbit anti-laminin Ab (Sigma, St. Louis, MO). The sections were rinsed for $2 \mathrm{hr}$ in PBS or in TBS three times for $10 \mathrm{~min}$ and incubated in a solution of $10 \%$ normal swine serum and $1 \%$ Triton $\mathrm{X}-100$. They were then incubated in $200 \times$ primary Ab for $1 \mathrm{hr}$. After rinsing, they were incubated in $500 \times$ fluorescein-conjugated swine anti-

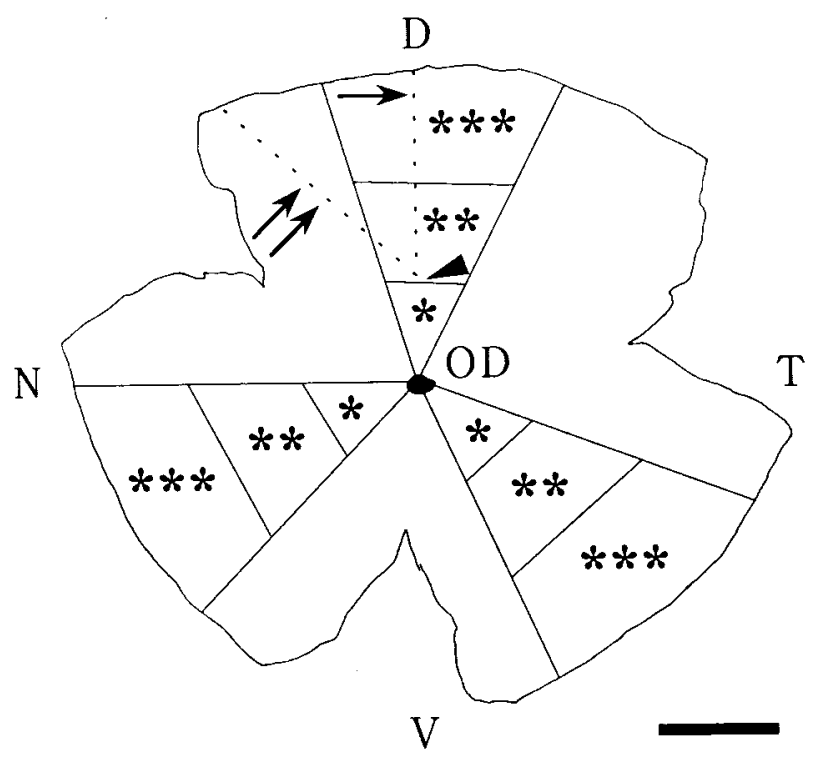

Figure 1. A schematic diagram showing how survival and axonal regeneration of RGCs were evaluated in retinal whole mounts of wt and bcl-2 mice after PN transplantation. In the case of RB transplantation, the survival and regeneration rates of RGCs were estimated by cell counting in three triangular regions bounded by the radial lines drawn from the optic disk $(O D)$ to the retinal margin. For the comparison of survival or axonal regeneration of RGCs among different eccentricities from the OD (see Fig. 5), each triangular region was divided into three congruent parts: center $(*)$, midperipheral $(* *)$, and peripheral $(* * *)$ retina. In the case of IR transplantation, a fan-like region in the dorsonasal retina, bounded by two dotted lines, served for the analysis. Their crossing (arrowhead), where the PN graft was inserted, was set at one-third from the OD to the retinal margin. The angle made by the lines was $55^{\circ}$. The bounded region corresponds to the presumed area of axotomy for IR transplantation. Scale bar, $1 \mathrm{~mm}$. $D$, Dorsal; $V$, ventral; $N$, nasal; $T$, temporal. 

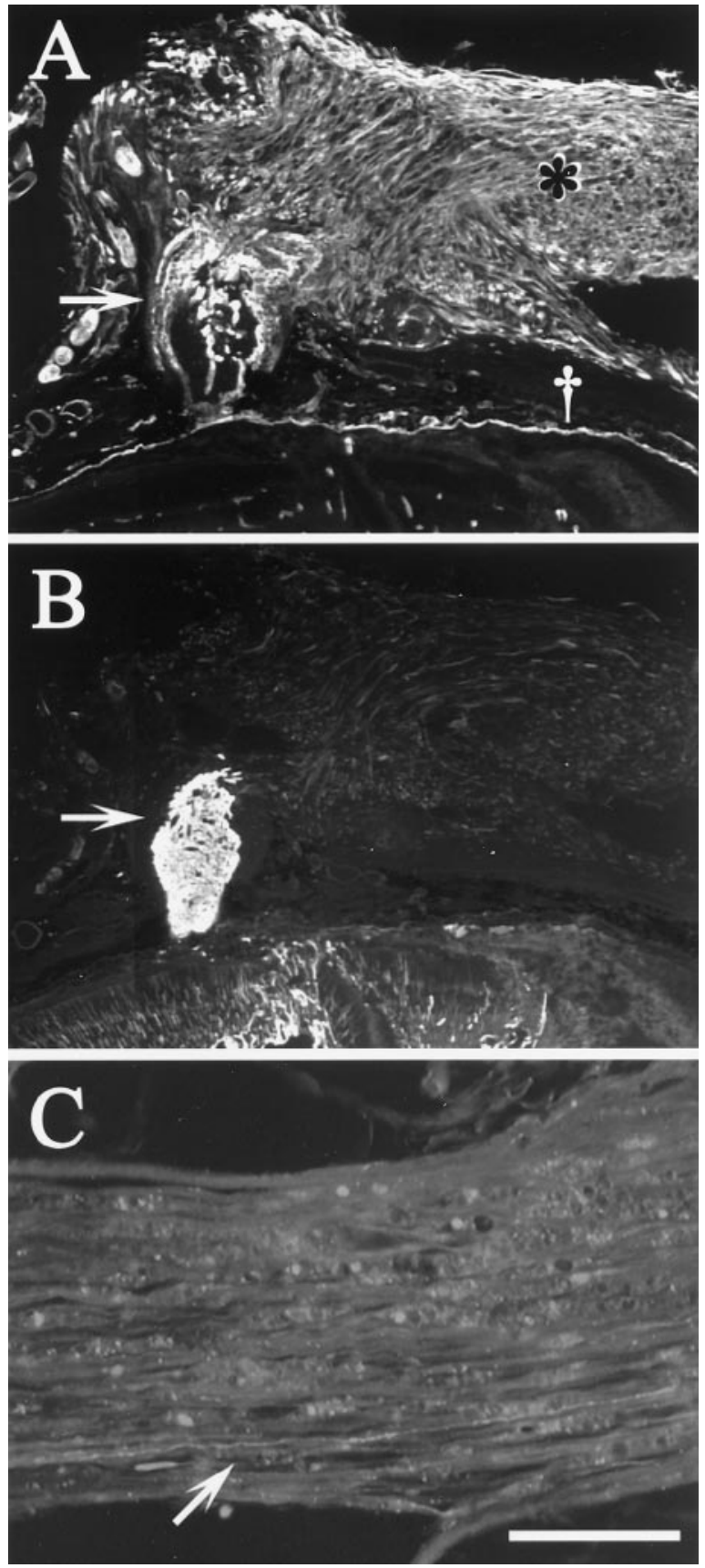

Figure 2. Longitudinal sections of the ON-PN interface and distal part of the PN graft of one wt mouse. $A$, The ON-PN interface immunostained with an antibody against laminin. The laminin-positive PN graft $(*)$ runs horizontally along the eye wall $(\dagger)$ and connects with the proximal ON stump (arrow). In the ON stump, only the meningeal sheath and the blood vessels are laminin-positive. $B$, The adjacent section immunostained for GFAP. The inner tissue of the ON stump is GFAP-positive (arrow). $C$, The distal part of the PN graft after anterograde labeling with rhodamine, with the focal point on a long fiber of regenerating RGC axon (arrow). Scale bar: $A, B, 160 \mu \mathrm{m} ; C, 100 \mu \mathrm{m}$.

rabbit immunoglobulins (Dako Japan) for $1 \mathrm{hr}$. They were mounted with the anti-fading reagent after thorough rinsing.

\section{$R B$ transplantation: assessing retrogradely labeled $R G C s$}

Labeling of normal RGCs. To determine whether a total population of normal RGCs was retrogradely labeled in nongrafted retina, we used a lipid-soluble dye, 1,1'-dioctadecyl-3,3,3',3'-tetramethyl-indocarbocyanine perchlorate (DiI) (Molecular Probes), for the labeling. The scalp of the animal was partially removed, and the bilateral occipital cortices were aspirated until the superior colliculi (SCs) were exposed. After removal of the meninges, pieces of DiI crystals were inserted into the SCs. Three weeks later, the right eye was enucleated and immersion-fixed in $4 \%$ paraformaldehyde for $20 \mathrm{~min}$. The retina was removed and whole-mounted with the radial slits on inferior, dorsonasal, and dorsotemporal retina. It was mounted on a glass slide and coverslipped with the anti-fading reagent.

Labeling of surviving RGCs. The RB transplantation was done 3 weeks after DiI-labeling of RGCs. After 4 week survival of transplanted animals, retinal whole mounts were made from the grafted eyes, and the DiI-labeled RGCs were counted in each retinal preparation.

Labeling of regenerating RGCs. To label RGCs that have axons regenerating along the $\mathrm{PN}$, we used the retrograde tracer rhodamine isothiocyanate dextran (dRITC) (Fluororuby, Molecular Probes). At 4 weeks after RB transplantation, the distal part of the PN graft was exposed and transected at a distance of $10 \mathrm{~mm}$ from the eyeball. A piece of gelatin sponge (Spongel, Yamanouchi, Tokyo, Japan) was immersed in a solution of $30 \%$ dRITC and $4 \%$ DMSO and inserted into the transection site. After $2 \mathrm{~d}$ survival, the animal was perfused with $4 \%$ paraformaldehyde and a retinal whole mount was made.

Assessment of cell counts of labeled RGCs. Retrogradely labeled RGCs were counted under epifluorescence illumination (E800, Nikon, Tokyo, Japan) at $400 \times$ magnification with a $10 \times 10 \mathrm{~mm}$ eyepiece graticule. The normal and surviving RGCs were counted in a square field $(250 \times 250$ $\mu \mathrm{m})$ of the graticule under the microscope. The first sampling field was positioned around the optic disk (OD) and after cell counting was successively done in every contiguous field in a horizontal direction toward temporal and nasal margins of the retina. Then the sampling fields were moved above and below the first sampling position at intervals of $500 \mu \mathrm{m}$. If necessary, additional series of vertically directed counting was done at intervals of $500 \mu \mathrm{m}$ from nasal and temporal margins of the retina. As a total, $>50 \%$ of the retinal surface area was sampled. On the drawing of the retinal whole mount, the cell counts were plotted as densities (cells per millimeters squared) at each location where the RGCs were sampled. From the plotted retinal drawing, we made the retinal density map by drawing isodensity lines. The total cell count was estimated by summation of each product [(isodensity value) $\times$ (isodensity area)]. In the case of regenerating RGCs, their real number was counted over the entire retinal surface. In $3 \mathrm{wt}$ and three $b c l-2$ mice, the location of the regenerating cells was charted on the drawing of the retinal whole mounts.

Assessing RGC survival. First, we evaluated the survival rates of RGCs in wt and $b c l-2$ mice from the retinal density maps of normal and surviving RGCs. As shown in Figure 1, the retinal density maps were separated into three areas: dorsal, ventronasal, and ventrotemporal. In each area, a triangular region was outlined by two radial lines drawn from the OD to the retinal margin. They made an angle of $45^{\circ}$ at the OD. The survival rate of RGCs (= [(density of surviving RGCs) $\times 100 /$ (density of normal RGCs)]) was calculated for each region. The survival rate per retina was then obtained by averaging the survival rates from the three regions. The number of surviving cells per retina was obtained as [(survival rate) $\times$ (number of normal RGCs)].

Assessing $R G C$ axonal regeneration. To evaluate the difference in ability of axonal regeneration between wt and $b c l-2$ mice, we calculated the following rates from the above cell counts. First, the regeneration rate of surviving RGCs was calculated from [(number of regenerating RGCs) $\times$ $100 /($ number of surviving RGCs)]. Second, the regeneration rate of intact RGCs was calculated from [(number of regenerating RGCs) $\times$ 100/(number of normal RGCs)].

Centri-peripheral gradient of survival and regeneration rates. We investigated the differences in survival (wt, $n=4 ; b c l-2, n=4)$ and regeneration (wt, $n=3 ; b c l-2, n=3$ ) rates at different distances between the RGC cell bodies and the lesioned site. To assess these rates, we used the retinal maps of normal RGCs and surviving RGCs and those on which the location of regenerating RGCs was charted. As shown in Figure 1, the three triangular regions outlined with two radial lines were further divided into three parts with two parallel lines that trisected the radial lines: central (single asterisk), midperipheral (double asterisks), and peripheral (triple asterisks) parts. In each part of the triangular regions, the survival rates and the regeneration rates of surviving RGCs were calculated from the cell densities. 

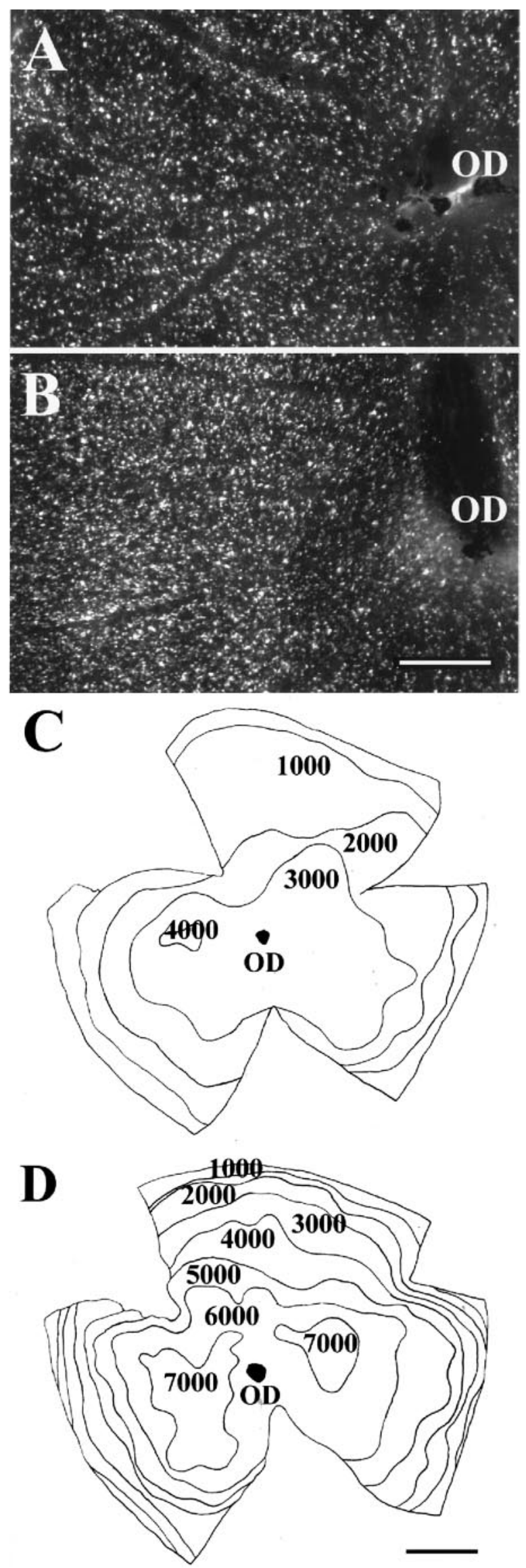

\section{RB transplantation: RT97 immunostaining for intraretinally regrowing axons}

To examine whether there were any retracting RGC axons that regrew within the retina after $\mathrm{RB}$ transplantation, we immunostained the retinal axons. The primary Ab was RT97 (Affiniti Research Products, Mamhead, UK), a mouse monoclonal Ab directed against the phosphorylated form of $200 \mathrm{kDa}$ neurofilaments in the axon. In the grafted animals, the retinal whole mounts were processed for RT97 staining after the dRITClabeled RGCs were counted. In a sterile tissue culture dish with 48 wells (Corning, Corning, NY), the retinal whole mounts were rinsed in PBS three times for $10 \mathrm{~min}$ and preincubated for $2 \mathrm{hr}$ in a solution of PBS, including $10 \%$ normal goat serum and $0.1 \%$ Triton X-100. They were then incubated in a solution of 1:200 or 1:500 dilution of RT97 with 10\% normal goat serum and $0.1 \%$ Triton X-100 for $15 \mathrm{hr}$. They were rinsed and further incubated for $2 \mathrm{hr}$ in a solution of 1:200 dilution of Cy3conjugated goat anti-mouse $\mathrm{IgG}$ with $10 \%$ normal goat serum and $0.1 \%$ Triton X-100. After the final rinse, they were mounted with the antifading reagent.

\section{IR transplantation: assessing $R G C$ axonal regeneration}

The procedures used to label regenerating RGCs and to prepare retinal whole mounts were as described above. After the cells were counted, five wt and four $b c l-2$ retinas were further processed for RT97 immunostaining.

\section{Analysis of cell counts}

As in a recent study of ours (Inoue et al., 2000), we estimated the number of intact RGCs in the presumed region of axotomy in IR transplantation. Briefly, in the retinal density maps of normal RGCs, the presumed axotomized region was outlined by two dotted segments in the dorsonasal retina as follows (Fig. 1). One segment was the peripheral twothirds of the vertical line (single arrow) that joined the OD and the retinal margin. Another was an oblique segment (double arrows) that joined the central end of the vertical segment and the retinal margin. The angle made by the two segments was $55^{\circ}$. The crossing of the segments (arrowhead) corresponded to the transplanted site. The location and area of axotomy $\left(1.5 \mathrm{~mm}^{2}\right)$ have been shown to be quite consistent throughout the intraretinally transplanted retinas (Inoue et al., 2000). On the basis of this finding, the regeneration rate of intact RGCs was calculated from [(number of dRITC-labeled RGCs) $\times 100 /$ (number of normal RGCs in the presumed axotomized region)].

\section{RESULTS}

\section{Attachment of the PN graft to the ON stump}

As shown previously, the regeneration rate of mouse RGC axons after PN transplantation is much lower than that in other mammalian species (Vidal-Sanz et al., 1987; Watanabe et al., 1993; Quan et al., 1999; Cui and Harvey, 2000; Inoue et al., 2000). This may be attributed to inadequate RB transplant operations with partially detached PN grafts. To address this possibility, we examined the ON-PN interface in longitudinal sections of the grafted site 4 weeks after RB transplantation in wt mice. In a typical section of the $\mathrm{ON}-\mathrm{PN}$ interface, laminin-positive Schwann cells were observed in the PN graft (Fig. $2 A$, asterisk), but not at a region close to the proximal end of the PN graft (Fig. $2 A$, arrow) where only the meningeal sheath and blood vessels were laminin-positive. This region corresponded to the proximal ON stump as indicated by GFAP-positive astrocytes in the adjacent section (Fig. 2B, arrow). These observations demonstrate

\footnotetext{
Figure 3. $A, B$, DiI-labeled RGCs in the temporal retina of wt $(A)$ and $b c l-2(B)$ mice, under epifluorescence illumination. These and all other micrographs are positive prints, in which DiI-fluorescence appears white. $C, D$, Isodensity maps of the retinal whole mounts of wt $(C)$ and $b c l-2(D)$ mice. The RGC density (cells per millimeters squared) in $b c l-2$ mice was approximately twice as much as that in wt mice throughout the retina. $O D$, Optic disk. Scale bar (shown in $B$ ): $A, B, 500 \mu \mathrm{m}$; (shown in $D$ ): $C$, $D, 1 \mathrm{~mm}$.
}

$\leftarrow$ 

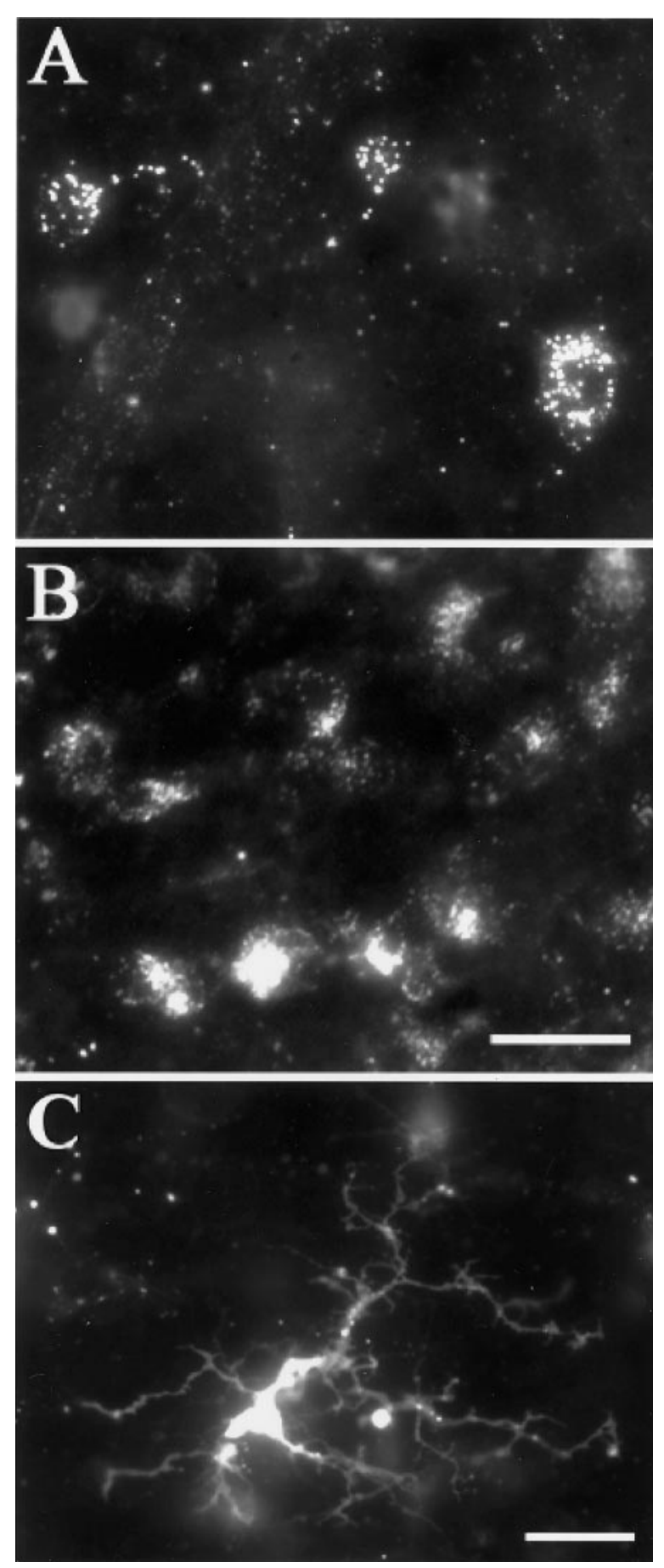

Figure 4. DiI-positive cells on the retina 4 weeks after RB transplantation, under epifluorescence illumination. $A, B$, Retrogradely labeled RGCs that contain many DiI granules in the retinas of wt $(A)$ and $b c l-2$ $(B)$ mice. These are RGCs that have survived the RB transplantation. Many more labeled RGCs appeared in $b c l-2$ mice than in wt mice. $C, \mathrm{~A}$ DiI-positive putative microglia showing a small and irregular cell body and some thick processes. Scale bars (shown in $B$ ): $A, B, 20 \mu \mathrm{m} ; C, 20 \mu \mathrm{m}$.

that the PN graft was continuously attached to the ON stump. At the distal part of the continuously attached PN graft $(5-10 \mathrm{~mm}$ away from the eyeball), a few regenerating axons were seen to course through the PN graft (Fig. $2 C$, arrow). Similar results were obtained in all three PN-grafted wt mice. Although the possibility of partial detachment of the PN grafts cannot be eliminated in

\begin{tabular}{|c|c|c|}
\hline & wt & $b c l-2$ \\
\hline $\begin{array}{l}\text { Density of normal RGCs } \\
\quad \text { (per millimeters squared) }\end{array}$ & $2495 \pm 227(n=3)$ & $4869 \pm 66(n=3)$ \\
\hline $\begin{array}{r}\text { Density of surviving RGCs } \\
\text { (per millimeters squared) }\end{array}$ & $144 \pm 14(n=5)$ & $3180 \pm 706(n=4)$ \\
\hline Survival rate $(\%)^{a}$ & $5.8 \pm 0.6$ & $65.3 \pm 14.5^{b}$ \\
\hline
\end{tabular}

${ }^{a}[100 \times($ density of surviving RGCs)/(density of normal RGCs)].

${ }^{b} t$ test; $\mathrm{df}=8 ; p<0.01$.

other RB transplanted mice, we infer that the ON-PN interface was well preserved and intact in $b c l-2$ mice as well, because procedures for PN transplantation were exactly the same for all animals.

\section{Higher survival rate of RGCs in bcl-2 mice after RB transplantation}

To assess the ability of RGCs to survive in wt and $b c l-2$ mice, we evaluated the survival rate of RGCs. First, we estimated the number of DiI-labeled normal RGCs in the retinas of wt and $b c l-2$ mice. The density of labeled RGCs appeared to be higher in $b c l-2$ mice (Fig. $3 B$ ) than in wt (Fig. $3 A$ ) mice. Then we made isodensity maps of labeled RGCs for the retinas of both wt and $b c l-2$ mice. As shown in Figure 3C, the cell density of wt mouse retina was highest around the OD (3000-4000 cells $\left./ \mathrm{mm}^{2}\right)$ and gradually decreased toward the peripheral retina (1000 cells/ $\mathrm{mm}^{2}$ ) in agreement with previous reports (Dräger and Olsen, 1980, 1981; Cenni et al., 1996). In bcl-2 mice, a similar gradient of RGC density was observed, but the density was more than twice that in wt mice throughout the whole retina (Fig. $3 D$ ): the highest density around the OD ranged from 6000 to 7000 cells $/ \mathrm{mm}^{2}$. From the density maps, the total numbers of RGCs were estimated to be $41,704 \pm 3,009$ (per retina, mean $\pm \mathrm{SD}, n=3$ ) for $\mathrm{wt}$ mice and 100,097 $\pm 7,831(n=3)$ for $b c l-2$ mice. The estimates of total RGCs were consistent with those of 45,400 and 112,400 ON fibers in the study of Cenni et al. (1996) on wt and bcl-2 mice, respectively.

Next, to assess RGC survival rates in wt and $b c l-2$ mice, we estimated the number of RGCs that survived 4 weeks after RB grafting. During the 4 week survival period, DiI-labeled RGCs that were undergoing cell death may have deteriorated and released DiI granules from their cell bodies. Because it is possible that these DiI granules may have been taken up by phagocytic cells such as microglia (for review, see Thanos et al., 1994), we took precautions not to count these as surviving RGCs. At 4 weeks after RB transplantation, DiI-positive RGCs characteristically had many DiI granules within their polygonal cell bodies in the retinal whole mounts of both wt (Fig. $4 A$ ) and $b c l-2$ mice (Fig. $4 B)$. By contrast, the putative microglia had small and irregular cell bodies and thick branching processes, morphologically distinct from the RGCs (Fig. 4C). We excluded such DiI-positive putative microglia from our counts of surviving RGCs.

Figure 4, $A$ and $B$, shows the DiI-positive surviving RGCs in comparable retinal areas that were free from the putative microglia at 4 weeks after RB transplantation. They appeared to be more numerous in $b c l-2$ mice (Fig. $4 B$ ) than in wt mice (Fig. 4A). To quantitatively assess the ability of RGCs to survive when $b c l-2$ is overexpressed, the survival rate was compared between wt and $b c l-2$ mice (Table 2). The mean densities of surviving RGCs were 
Table 3. Regeneration rates of RGCs after RB transplantation in wt and $b c l$-2 mice

\begin{tabular}{lrr} 
& wt & $b c l-2$ \\
\hline Number of regenerated RGCs & $185 \pm 96(n=9)$ & $343 \pm 109(n=9)$ \\
Number of surviving RGCs ${ }^{a}$ & $2412 \pm 235(n=5)$ & $65,370 \pm 14,513(n=4)$ \\
Number of normal RGCs & $41,704 \pm 3009(n=3)$ & $100,097 \pm 7831(n=3)$ \\
Regeneration rate of surviving RGCs $(\%)^{b}$ & $7.7 \pm 4.0^{*}$ & $0.5 \pm 0.3$ \\
Regeneration rate of intact RGCs $(\%)^{c}$ & $0.4 \pm 0.2$ & $0.3 \pm 0.2$ \\
\hline
\end{tabular}

${ }^{*} t$ test; df $=8 ; p<0.01$.

${ }^{a}[($ survival rate) $($ see Table 2$) \times($ number of normal RGCs $)]$.

${ }^{b}[100 \times$ (number of regenerated RGCs)/(number of surviving RGCs) $]$.

${ }^{c}[100 \times$ (number of regenerated RGCs)/(number of normal RGCs)].

$144 \pm 14$ cells $/ \mathrm{mm}^{2}(n=5)$ in WT mice and $3180 \pm 706$ cells $/ \mathrm{mm}^{2}$ in $b c l-2$ mice $(n=4)$. The survival rates of RGCs evaluated by dividing these density values by those of normal RGCs (wt: $2495 \pm 227$ cells $/ \mathrm{mm}^{2}, n=3 ;$ bcl-2: $4869 \pm 66, n=3$ ) were $5.8 \pm$ $0.6 \%$ in wt mice and $65.3 \pm 14.5 \%$ in $b c l-2$ mice. This higher survival rate in $b c l-2$ mice agreed quite well with that reported by Cenni et al. (1996).

\section{Lower regeneration rate of RGCs in bcl-2 mice after RB transplantation}

To assess the numbers of axon-regenerating RGCs in wt and $b c l-2$ mice, we evaluated their regeneration rates as follows. First, in the whole-mount retina, we counted the number of regenerating RGCs that were retrogradely labeled with dRITC from the PN graft. The mean numbers of regenerating RGCs were $185 \pm 96$ $(n=9)$ in wt mice and $343 \pm 109(n=9)$ in $b c l-2$ mice (Table 3$)$. Second, from the product [(number of normal RGCs) $\times$ (survival rate)] (Table 2), we found the mean numbers of surviving RGCs to be $2412 \pm 235(n=5)$ in wt mice and 65,370 $\pm 14,513(n=4)$ in bcl-2 mice (Table 3). Finally, from the ratio of the number of regenerating RGCs to the number of surviving RGCs, we found the regeneration rates of surviving RGCs to be $7.7 \pm 4.0 \%$ in wt mice and $0.5 \pm 0.3 \%$ in $b c l-2$ mice (Table 3 ). Thus the regeneration rate in $b c l-2$ mice was unexpectedly much lower than that in wt mice $(t$ test; $p<0.01)$. This finding indicates that the majority of the surviving RGCs in $b c l-2$ mice failed to regenerate their axons.

We further examined whether the axon regeneration rate (relative to the normal RGC population) was improved in $b c l-2$ mice because the number of surviving RGCs was higher or because the population of normal RGCs was larger. To know the regeneration rate of intact RGCs, we evaluated the number of regenerating RGCs as a fraction of the normal RGC population in each wt and $b c l-2$ mouse (Table 3$)$. The mean regeneration rates were $0.4 \pm 0.2 \%$ in wt mice and $0.3 \pm 0.2 \%$ in $b c l-2$ mice, indicating no significant difference in the number of regenerating RGCs between these mice (Table 3). Thus the RGC axonal regeneration was not better in $b c l-2$ mice than that in wt mice, regardless of the fact that $b c l-2$ mice have $>10$ times the number of surviving RGCs or more than twice the total population of normal RGCs.

\section{Centri-peripheral gradient of survival and regeneration rates}

Previous studies have shown that when neurons are axotomized closer to their cell bodies, the risk of cell death is higher and yet the chance of axonal regeneration is also higher than in distally axotomized cells (for review, see Herdegen et al., 1997). Consistent with this finding, in the previous study on RB transplanted ferret retinas, RGC survival was lower in the central than in

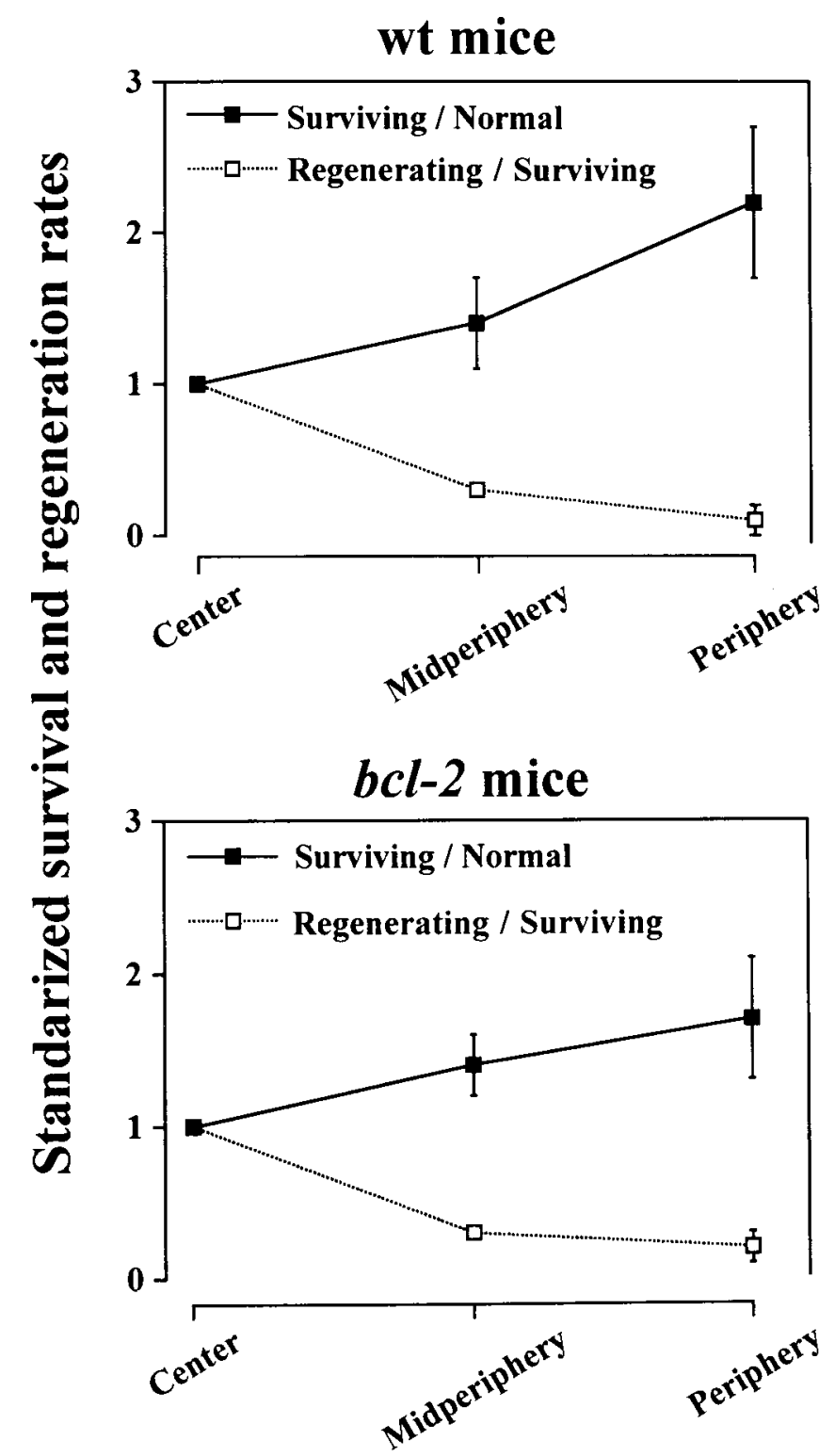

Figure 5. Centri-peripheral gradient of survival and regeneration rates of RGCs after RB transplantation. The vertical axis plots the rates normalized to the survival and regeneration rates of RGCs in the central retina. The total numbers of regenerated RGCs used in this analysis were 228,121 , and 117 cells in wt mice and 658, 598, and 237 cells in bcl-2 mice. In both wt and $b c l-2$ mice, the survival rate tends to increase toward the periphery (wt, $n=4 ; b c l-2, n=4$ ), whereas the regeneration rate tends to decrease (wt, $n=3 ; b c l-2, n=3$ ). 

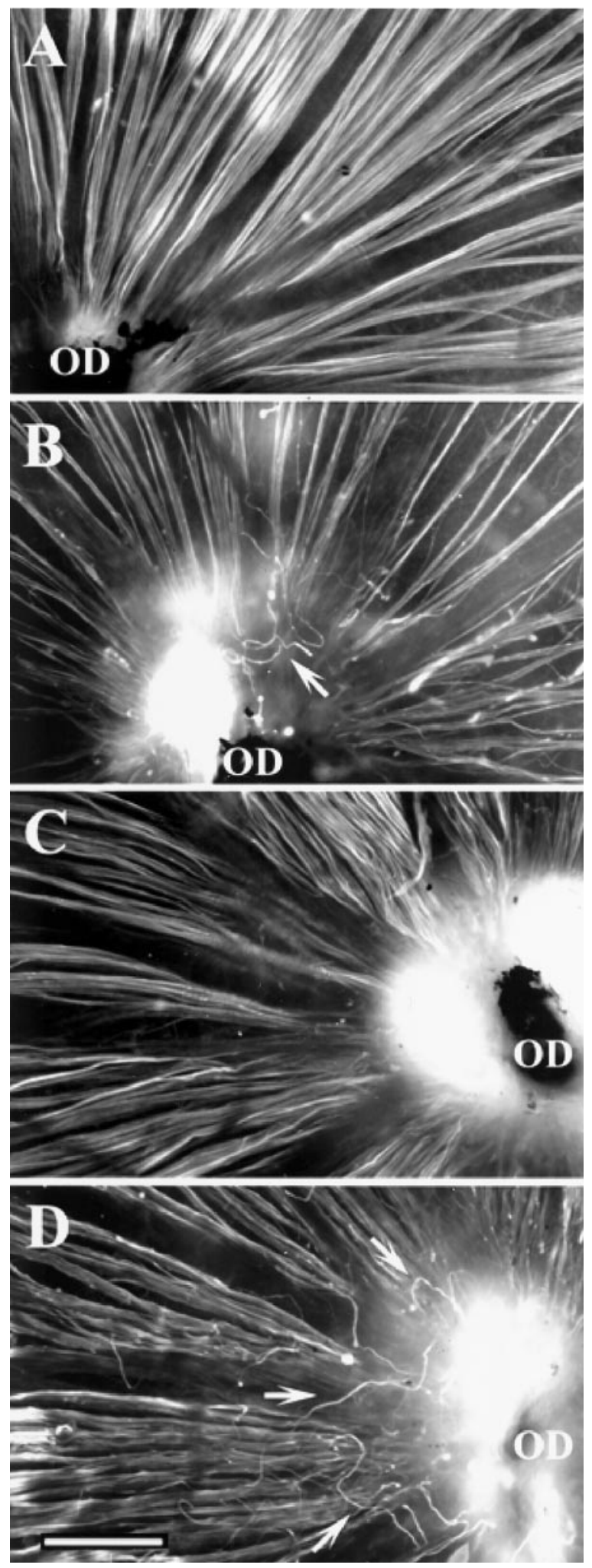

Figure 6. Epifluorescence micrographs of retinal whole mounts treated with RT97 immunostaining. In the nongrafted retinas of wt $(A)$ and $b c l-2$ $(B)$ mice, all RT97-positive RGC axons showed many fasciculated fibers that run centripetally toward the optic disk $(O D)$. However, 4 weeks after RB transplantation, some regrowing RGC axons form a complex of looping fibers near the OD (see arrows in $B$ for wt and in $D$ for $b c l-2$ mice). In comparison with the normal fasciculated fibers, these looping fibers do not appear to be more numerous on $b c l-2$ retina than on wt retina. Scale bar, $200 \mu \mathrm{m}$. peripheral retina (Quan et al., 1999). In the present experiment, we asked how $b c l-2$ overexpression affected the centri-peripheral gradient of the survival and axonal regeneration of RGCs. From the density maps of the DiI-labeled surviving RGCs and the dot maps of the dRITC-labeled regenerating RGCs, the difference in survival and regeneration rates among central, midperipheral, and peripheral retina was compared between wt and $b c l-2$ mice. These rates were normalized so that the rate in the central retina would be 1.0. In both wt and $b c l-2$ mice, the mean survival rates tended to increase from central to peripheral retina (wt: midperiphery $=1.5 \pm 0.3$, periphery $=2.2 \pm 0.5, n=4 ;$ bcl-2: midperiphery $=1.4 \pm 0.2$, periphery $=1.7 \pm 0.4, n=4)$ (Fig. 5). Thus the centri-peripheral gradient of RGC survival seemed to be preserved in $b c l-2$ mice as well. As for the regeneration rates of surviving RGCs, they appeared to decrease drastically from central to peripheral retina in both wt and $b c l-2$ mice (wt: midperiphery $=0.3 \pm 0.0$, periphery $=0.1 \pm 0.1, n=3 ;$ bcl-2: midperiphery $=0.3 \pm 0.0$, periphery $=0.2 \pm 0.1, n=3$ ) (Fig. 5). Thus there was no indication that $b c l-2$ overexpression improved the relative ability of RGC axons to regenerate in the midperipheral and peripheral regions because the centri-peripheral gradient in $b c l-2$ mice seemed to be preserved for RGC regeneration as well as that in wt mice.

\section{Repulsion of intraretinal axonal regrowth at the $O D$}

After ON transection, some RGC axons undergo retraction from the ON stump into the retina and after intraretinal regrowth that results in repulsion around the OD (Sawai et al., 1996). This repulsive activity can prevent the axonal regrowing of RGCs into the PN graft and their contribution to axonal regeneration. These axons are observed as irregular and unfasciculated fibers that loop around the OD in RT97-immunostained retinal whole mounts (Mansour-Robaey et al., 1994). We asked here whether RGC axons that had been severed after RB transplantation retracted and regrew within the retinas of $b c l-2$ mice. In the intact retinas of wt (Fig. 6A) and bcl-2 mice (Fig. 6C), many RT97positive fibers emanated radially from the OD in a fasciculated manner. Even at 4 weeks after RB transplantation, most radial fibers in $b c l-2$ mice still appeared to be fasciculated (Fig. 6D), whereas those in wt mice became markedly sparse (Fig. 6B). This finding is consistent with the higher RGC survival rate in $b c l-2$ mice that was quantitatively evaluated above. The notable finding was that the complexity of unfasciculated fibers that looped around the OD (Figs. 6B,D, arrows) was apparent not only in wt but also in bcl-2 mouse retinas. As described above, the axonal retraction after the repulsed regrowth was expected in wt mice from the previous observations by Mansour-Robaey et al. (1994). Our observation of the retinas in $b c l-2$ mice indicated that some RGC axons behaved in the same way as those in wt mice after ON transection. Thus it is possible that this has contributed to the lower RGC regeneration rate of surviving RGCs in $b c l-2$ mice. However, we had an impression that the occurrence of these fibers in $b c l-2$ mice was not more frequent than that in wt mice, although we did not assess the number of these looping fibers quantitatively. This finding allowed us to speculate that even after a severe lesion (i.e., proximal ON cut), most injured axons were able to persist in the proximal ON stump as well as in the case of a mild lesion (i.e., distal ON crush) that has been examined by Chierzi et al. (1999). 


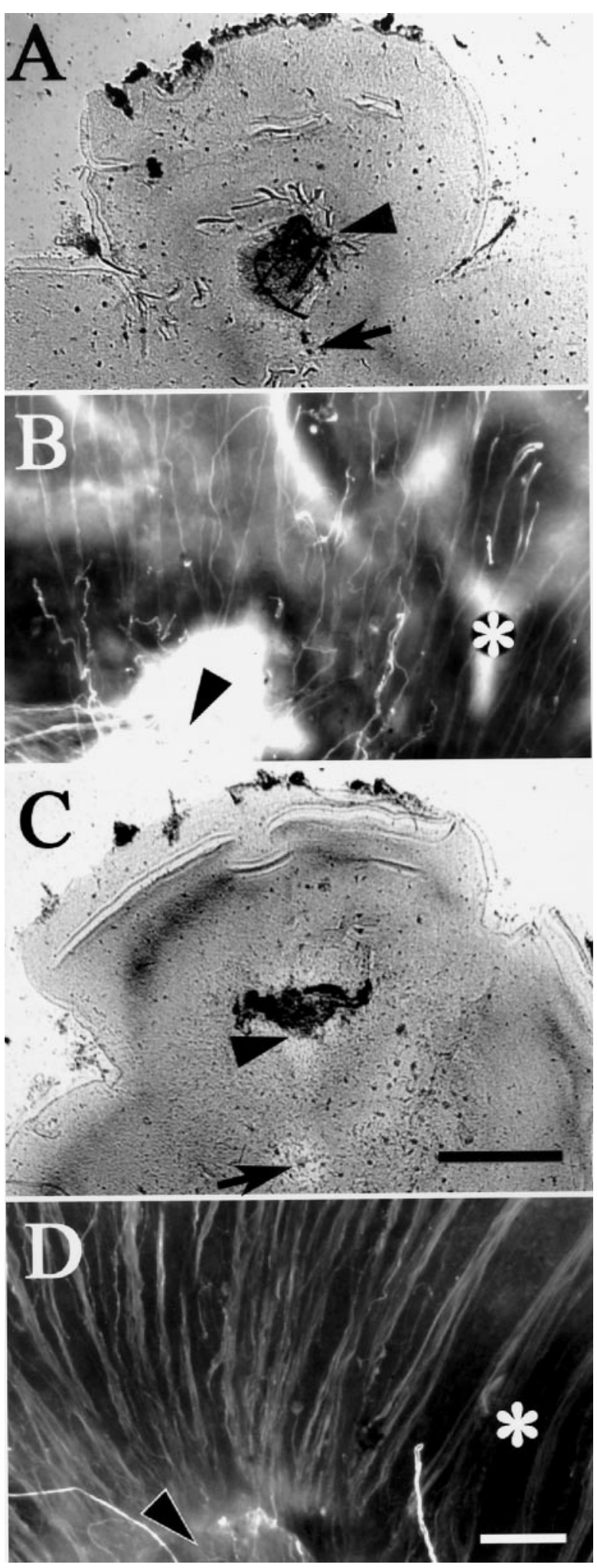

Figure 7. Retinal whole mounts $(A, C)$ and RT97-immunostained retinal axons $(B, D) 4$ weeks after IR transplantation. $A, B$, Left retina of a wt mouse. $C, D$, Right retina of a $b c l-2$ mouse. $A, C$, In both retinas, the PNs are positioned at similar sites in the dorsonasal retina (see Fig. 1). Positions of the optic disk and the PN graft are indicated with an arrow and an arrowhead, respectively. $B, D$, Epifluorescence micrographs of RT97-positive RGC axons in each retina: in the dorsal retina distal to the PN graft, many axons reach the graft (arrowhead) in both mice. Apparently no RGC axons that have reached the PN graft loop near the PN
Table 4. Regeneration rates of RGCs after IR transplantation in wt and $b c l-2$ mice

\begin{tabular}{lll} 
& $\mathrm{wt}$ & $b c l-2$ \\
\hline $\begin{array}{l}\text { Number of normal RGCs } \\
\text { Median number of regen- } \\
\quad \text { erated RGCs }\end{array}$ & $2122 \pm 43(n=3)$ & $4738 \pm 719(n=3)$ \\
$\begin{array}{l}\text { Median regeneration rate } \\
(\%)^{b}\end{array}$ & $1.6(1.1-3.6)$ & $41(31-81 ; n=6)$ \\
\end{tabular}

${ }^{a}$ Estimated on the presumed axotomy area for IR transplantation.

${ }^{b}[100 \times($ number of regenerated RGCs)/(number of normal RGCs) $]$.

\section{No superiority of axonal regeneration in $b c l-2$ mice even in IR transplantation}

To make the axotomized RGCs access to the PN graft directly, we bypassed the repulsive environment around the OD by using another transplant method, IR transplantation. With this method, the ends of the PN grafts (Figs. $7 A-D$, arrowheads) were positioned at similar sites on the dorsonasal retinas of wt (Fig. $7 A$ ) and $b c l-2$ mice (Fig. $7 C$ ). At the distal parts of the grafted site, RT97-immunopositive fibers in wt (Fig. 7B) and bcl-2 (Fig. 7D) retinas were visible at higher magnification. Many fasciculated RT97-positive fibers coursed toward the PN graft (arrowhead) in bcl-2 mice (Fig. 7D), in contrast with the sparse and thin RT97positive fibers of wt mice (Fig. $7 B$ ). This suggests that a large number of RGC axons were maintained after IR transplantation in $b c l-2$ mice as in the case of RB transplantation. There was no looping axon noticed around the PN graft (Figs. $7 B, D$, arrowhead) in both mice, in contrast to RB-transplanted retinas (see Figs. $6 B, D$ ). This finding suggests that IR transplantation provided a more permissive environment for axonal regrowth into the PN graft. It supports our previous report (Inoue et al., 2000) showing improved regeneration rate in IR transplantation over that in RB transplantation. In contrast, in some IR-transplanted retinas of wt and $b c l-2$ mice, many RT97-positive fibers showed not only axonal looping around the grafted site but also axonal retraction away from the grafted site and swelling of axon terminals (data not shown). As reported previously, such behavior of severed RGC axons suggests that these axons have lost their proper regrowing pathway or undergo axonal degeneration (McConnell and Berry, 1982). This behavior could be caused by a barrier such as poor attachment of the PN graft to the retina and extensive scarring of retinal astrocytes. Consistently, these retinas showed only a few regenerating RGCs that were labeled with dRITC (data not shown). By excluding these retinas from this study, we minimized the influence of the putative barrier around the grafted site.

Under the more permissive condition of IR-transplanted retinas, we again assessed axonal regeneration of RGCs. The median cell counts of dRITC-labeled RGCs were 33 (range, 23-76; $n=$ 6 ) in WT mice and 41 in $b c l-2$ mice (range, $31-81 ; n=6$ ) (Table 4). We next evaluated the regeneration rates against the total numbers of intact RGCs in the intact wt and $b c l-2$ mice retinas as we did in our previous study (Inoue et al., 2000). In the presumed

graft (compare the photographs in Fig. 6). Because the focus is on the retinal fiber layer, the distal part of the RGC axons that enter the PN graft is not shown clearly. RGC axons in the neighboring area (*) are uninjured, and they course toward the optic disk. Scale bars: $A, C, 1 \mathrm{~mm} ; B, D$, $100 \mu \mathrm{m}$. 
axotomized area of $1.5 \mathrm{~mm}^{2}$ in the intact retina (Fig. 1, dorsonasal area outlined by the dot segments), the total numbers of normal RGCs were estimated to be $2122 \pm 43(n=3)$ in wt mice and $4738 \pm 719(n=3)$ in $b c l-2$ mice (Table 4$)$. The median regeneration rates $[=($ number of regenerating $\mathrm{RGCs}) \times 100 /$ (total number of normal RGCs)] were $1.6 \%(1.1-3.6 \%)$ in wt and $0.9 \%(0.7-1.7 \%)$ in $b c l-2$ mice (Table 4$)$. There was no significant difference between these mice. Thus the regeneration rates in wt and $b c l-2$ mice merely increased similarly (wt, fourfold; $b c l-2$, threefold), although IR transplantation did improve RGC axonal regeneration over $\mathrm{RB}$ transplantation in both mice. As observed in RB transplantation, therefore, the axonal regeneration of $b c l$ 2-overexpressed RGCs was not enhanced even in IR transplantation.

\section{DISCUSSION}

In the present study, we compared adult $b c l-2$ and wt mice to ask whether the neuroprotective effect of $b c l-2$ overexpression could also induce robust axonal regeneration of adult mammalian RGCs after PN grafting. To quantitatively assess the ability of axonal regeneration between $b c l-2$ and wt mice, we compared the number of RGCs labeled retrogradely from the PN graft that was transplanted to the cut end of the $\mathrm{ON}$ in the orbit, i.e., $\mathrm{RB}$ transplantation, after 4 weeks of survival. Although the survival rate of axotomized RGCs in $b c l-2$ mice was $>10$ times higher than that in wt mice, the regeneration rate of surviving RGCs in the $b c l-2$ mice was less than one-tenth of that in wt mice. Even when the regeneration rate was evaluated against the total number of RGCs in each mouse, the regeneration rate in $b c l-2$ mice did not exceed that in wt mice. We further assessed the ability of bcl-2-overexpressed RGCs to regenerate their axons by another method of PN transplantation, i.e., IR transplantation, which directly apposed the PN graft to the axotomized RGCs, providing them with a more permissive environment for axonal regeneration. Despite the more permissive environment, the regeneration rate in $b c l-2$ mice once again did not exceed that in wt mice. From these findings we concluded that $b c l-2$ overexpression does not enhance axonal regeneration of adult RGCs in vivo despite its remarkable effect on promoting RGC survival.

The present conclusion contradicts that of Chen et al. (1997) who have reported that $b c l-2$ overexpression itself promotes axonal regeneration of RGCs in in vitro coculture preparations of the retina and tectal tissues of different ages as well as in in vivo optic tract-sectioned $b c l-2$ mice. On the other hand, our study is consistent with a previous study of adult $b c l-2$ mice by Chierzi et al. (1999), who reported that local axonal sprouting, but not axonal regeneration, was promoted in RGCs after ON crush, even after the myelin-associated inhibitory factor was inactivated with IN-1. Furthermore, Lodovichi et al. (2001) found in neonatal (P5) bcl-2 mice that RGC axons did not regenerate through the crushed $\mathrm{ON}$ even in a period before the major myelin formation of RGC axons. In contrast to the adult ON treated with IN-1, however, robust RGC sprouting did not seem to occur at the ON stump proximal to the crushed site, which suggests the possible presence of additional inhibitory factors in the P5 ON. To surpass this inhibitory environment in the crushed ON, they implanted Schwann cells and demonstrated the successful axonal regeneration of RGC axons through the crushed site. Similarly, Goldberg and Barres (2000) have reported in a recent review that most of the RGCs dissociated from E19 and P8 rats and transfected with $b c l-2$ gene-containing vectors did not extend their neurites in the medium unless various neurotrophic factors were administered to the medium. These results suggest that providing a trophic environment may indeed be quite effective for inducing axonal regeneration of bcl-2-overexpressed RGCs.

In our quantitative study on axonal regeneration in $b c l-2$ mice by means of transplanting a PN graft, an environment permissive for axonal regeneration, there was no indication of a significant enhancement in the regeneration rate of RGCs by $b c l-2$ overexpression. One might argue that a poor apposition of the PN graft to the cut ON stump has led to such low regeneration rates of RGCs in the bcl-2 mice. As shown in Figure 2, however, we verified the tissue continuity of the ON-PN interface on longitudinal sections in wt mice. Thus it is unlikely that many of the PN grafts were detached in $b c l-2$ mice that underwent the same surgical procedures. Another possibility is that insufficient retrograde labeling of regenerating RGCs has resulted in the apparent small number of regenerating RGCs. However, using anterograde labeling with rhodamine, we further demonstrated in longitudinal sections of the continuously transplanted PN graft that only a few regenerating RGC axons grew through the PN graft (Fig. $2 C$ ). Thus our results suggest that $b c l-2$ overexpression by itself does not appear to enhance the axonal regeneration of RGCs through a permissive environment in the PN graft.

Why are so many RGCs rescued from cell death by overexpression of the $b c l-2$ gene unable to regenerate their axons? It is quite likely that the ability of RGCs to survive is not in tandem with their ability to regenerate axons. In other words, $b c l-2$ overexpression exerts a strong survival-promoting effect on axotomized RGCs by inhibiting downstream caspases but may not simultaneously activate the growth-promoting signaling pathway in these cells. The $b c l-2$ anti-apoptotic cascade is most likely separate from and cannot cross-talk with specific intracellular signaling pathways such as Ras-MAP kinase pathways activated by neurotrophin Trk receptors (for review, see Segal and Greenberg, 1996). Alternatively, the RGCs protected by $b c l-2$ overexpression may be the cells in excess that are normally programmed to die but are forced to survive without the ability to regenerate their axons. In support of this, Cenni et al. (1996) have reported that a large number of bcl-2-overexpressed surviving RGCs had shrunken cell bodies after ON cut and appeared to undergo atrophy.

From the therapeutic point of view, the inhibition of caspases by $b c l-2$ overexpression, caspase inhibitors, or bax antisense oligonucleotides (Kermer et al., 1998; Isenmann et al., 1999) would be the favored method for rescuing injured adult RGCs. According to our present study, however, such neuroprotective strategy appears to be insufficient for a robust axonal regeneration of RGCs in adult mammals. In other words, additional means that could activate intrinsic growth-signaling pathways of axotomized RGCs may be essential. In this respect, elevation of responsiveness to neurotrophins by forskolin (Meyer-Franke et al., 1998) and application of growth-promoting factors such as CNTF (Cui et al., 1999) may be effective strategies. Disinhibiting axonal growth by rho-inactivation (Lehmann et al., 1999), extrinsic manipulations of the inhibitory environment such as regulating the activities of non-neuronal cells (Thanos et al., 1993; LazarovSpiegler et al., 1996), and local induction of cell adhesion molecules (Izumoto et al., 1998; Bates et al., 1999) may also contribute to a more robust axonal regeneration.

In summary, our present quantitative study on adult $b c l-2$ mice indicated that the number of RGCs with regenerating axons did not increase over control levels even in a permissive environment in the PN graft. Supporting the previous studies by Chierzi et al. 
(1999) and Lodovichi et al. (2001), we conclude that $b c l-2$ overexpression does not promote in vivo axonal regeneration of adult RGCs. Furthermore, our present study strongly suggests that the increased number of surviving cells by $b c l-2$ overexpression cannot contribute to increasing the number of axon-regenerated RGCs.

\section{REFERENCES}

Bähr M (2000) Live or let die: retinal ganglion cell death and survival during development and in the lesioned adult CNS. Trends Neurosci 23:483-490.

Bates CA, Becker CG, Miotke JA, Meyer RL (1999) Expression of polysialylated NCAM but not L1 or N-cadherin by regenerating adult mouse optic fibers in vitro. Exp Neurol 155:128-139.

Cenni MC, Bonfanti L, Martinou J-C, Ratto GM, Strettoi E, Maffei L (1996) Long-term survival of retinal ganglion cells following optic nerve section in adult bcl-2 transgenic mice. Eur J Neurosci 8:1735-1745.

Chen DF, Schneider GE, Martinou J-C, Tonegewa S (1997) Bcl-2 promotes regeneration of severed axons in mammalian CNS. Nature 385:434-439.

Chierzi S, Strettoi E, Cenni MC, Maffei L (1999) Optic nerve crush: axonal responses in wild-type and bcl-2 transgenic mice. J Neurosci 19:8367-8376.

Cui Q, Harvey AR (2000) CNTF promotes the regrowth of retinal ganglion cell axons into murine peripheral nerve grafts. NeuroReport 11:3999-4002.

Cui Q, Lu Q, So K-F, Yip HK (1999) CNTF, not other trophic factors, promotes axonal regeneration of axotomized retinal ganglion cells in adult hamsters. Invest Ophthalmol Vis Sci 40:760-766.

Dräger UC, Olsen JF (1980) Origin of crossed and uncrossed retinal projections in pigmented and albino mice. J Comp Neurol 191:383-412.

Dräger UC, Olsen JF (1981) Ganglion cell distribution in the retina of the mouse. Invest Ophthalmol Vis Sci 20:285-293.

Goldberg JL, Barres BA (2000) The relationship between neuronal survival and regeneration. Annu Rev Neurosci 23:579-612.

Herdegen T, Skene P, Bähr M (1997) The c-Jun transcription factor: bipotential mediator of neuronal death, survival and regeneration. Trends Neurosci 20:227-231.

Hosokawa M, Inoue T, Fukuda Y (1999) Can Bcl-2 facilitate in vivo axonal regeneration of retinal ganglion cells in adult mice? Invest Ophthalmol Vis Sci 40:S131.

Inoue T, Sasaki H, Hosokawa M, Fukuda Y (2000) Axonal regeneration of mouse retinal ganglion cells by peripheral nerve transplantation; a quantitative study. Restor Neurol Neurosci 17:23-29.

Isenmann S, Engel S, Gillardon F, Bähr M (1999) Bax antisense oligonucleotides reduce axotomy-induced retinal ganglion cell death in vivo by reduction of Bax protein expression. Cell Death Differ 6:673-682.

Izumoto S, Ohnishi T, Hirano S, Hiraga S, Arita N (1998) Neural cell adhesion molecule L1 promotes regeneration of injured optic nerve of rats. Restor Neurol Neurosci 12:247-254.

Kermer P, Klocker N, Labes M, Bähr M (1998) Inhibition of CPP32-like proteases rescues axotomized retinal ganglion cells from secondary cell death in vivo. J Neurosci 18:4656-4662.

Lazarov-Spiegler O, Solomon AS, Zeev-Brann AB, Hirschberg DL, Lavie V, Schwartz M (1996) Transplantation of activated macrophages overcomes central nervous system regrowth failure. FASEB J 10:1296-1302.
Lehmann M, Fournier A, Selles-Navarro I, Dergham P, Sebok A, Leclerc N, Tigyi G, McKerracher L (1999) Inactivation of Rho signaling pathway promotes CNS axon regeneration. J Neurosci 19:7537-7547.

Lodovichi C, Di Cristo G, Cenni MC, Maffei L (2001) Bcl-2 overexpression per se does not promote regeneration of neonatal crushed optic fibers. Eur J Neurosci 13:833-838.

Mansour-Robaey S, Clarke DB, Wang Y-C, Bray GM, Aguayo AJ (1994) Effects of ocular injury and administration of brain-derived neurotrophic factor on survival and regrowth of axotomized retinal ganglion cells. Proc Natl Acad Sci USA 91:1632-1636.

Martinou J-C, Dubois-Dauphin M, Staple JK, Rodriguez I, Frankowski H, Missotten M, Albertini P, Talabot D, Catsicas S, Pietra C, Huarte J (1994) Overexpression of $\mathrm{Bcl}-2$ in transgenic mice protects neurons from naturally occurring cell death and experimental ischemia. Neuron 13:1017-1030.

McConnell P, Berry M (1982) Regeneration of ganglion cell axons in the adult mouse retina. Brain Res 241:362-365.

Mey J, Thanos S (1993) Intravitreal injections of neurotrophic factors support the survival of axotomized retinal ganglion cells in adult rats in vivo. Brain Res 602:304-317.

Meyer-Franke A, Wilkinson GA, Kruttgen A, Hu M, Munro E, Hanson MG, Reichardt LF, Barres BA (1998) Depolarization and cAMP elevation rapidly recruit TrkB to the plasma membrane of CNS neurons. Neuron 21:681-693.

Quan MZ, Kosaka J, Watanabe M, Wakabayashi T, Fukuda Y (1999) Survival of axotomized retinal ganglion cells in peripheral nervegrafted ferrets. Invest Ophthalmol Vis Sci 40:2360-2366.

Sasaki H, Inoue T, Iso H, Fukuda Y, Hayashi Y (1993) Light-dark discrimination after sciatic nerve transplantation to the sectioned optic nerve in adult hamsters. Vision Res 33:877-880.

Sawai H, Clarke DB, Kittlerova P, Bray GM, Aguayo AJ (1996) Brainderived neurotrophic factor and neurotrophin-4/5 stimulate growth of axon branches from regenerating retinal ganglion cells. J Neurosci $15: 3887-3894$

Segal RA, Greenberg ME (1996) Intracellular signaling pathways activated by neurotrophic factors. Annu Rev Neurosci 19:463-489.

So K-F, Aguayo AJ (1985) Lengthy regrowth of cut axons from ganglion cells after peripheral nerve transplantation into the retina in adult rats. Brain Res 328:349-354.

Thanos S (1992) Adult retinofugal axons regenerating through peripheral nerve grafts can restore the light-induced pupilloconstriction reflex. Eur J Neurosci 4:691-699.

Thanos S, Vidal-Sanz M, Aguayo AJ (1987) The use of rhodamine-Bisothiocyanate (RITC) as an anterograde and retrograde tracer in the adult visual system. Brain Res 406:317-321.

Thanos S, Mey J, Wild M (1993) Treatment of the adult retina with microglia-suppressing factors retards axotomy-induced neuronal degradation and enhances axonal regeneration in vivo and in vitro. J Neurosci 13:455-466.

Thanos S, Kacza J, Seeger J, Mey J (1994) Old dyes for new scopes: the phagocytosis-dependent long-term fluorescence labelling of microglial cells in vivo. Trends Neurosci 17:177-182.

Vidal-Sanz M, Bray GM, Villegas-Pérez MP, Thanos S, Aguayo AJ (1987) Axonal regeneration and synapse formation in the superior colliculus by retinal ganglion cells in the adult rat. $\mathrm{J}$ Neurosci 7:2894-2909.

Watanabe M, Sawai H, Fukuda Y (1993) Number, distribution, and morphology of retinal ganglion cells with axons regenerated into peripheral nerve graft in adult cats. J Neurosci 13:2105-2117. 